\title{
The semantic structure of Pejoratives
}

\author{
Nenad Mišćević (Maribor/Budapest)
}

\begin{abstract}
Pejoratives find their place in the context of linguistic violence and offensive speech, and a theory of pejoratives thus should be connected to the (im-)politeness research. Here, they are put on the map of generic expressions, and characterized as negative evaluative generic terms. The parallel between pejoratives and laudatory expressions is noted. Pejoratives have a rich semantics: causal-descriptive securing of reference, and several layers of non-descriptive meaning, mainly negative-evaluative and prescriptive (the expressive meaning might be part of pragmatics). They are hybrid negative social kind terms. Therefore, a pejorative generic sentence normally expresses several propositions, some of them true, some false, each to be selected by relevant context. Pejoratives stand at the intersection of three areas of research: generics, semantics of pejoratives (and of laudatory expressions) and the (im-)politeness theory in social pragmatics, and the three need to be brought together.
\end{abstract}

\section{Introduction}

The topic of the conference has been "Language and violence". ${ }^{1}$ Linguistic violence is an extreme form of impoliteness-rudeness and addressed in the literature belonging to politeness theory. ${ }^{2}$ Jonathan Culpeper who has been, in his Impoliteness: Using Language to Cause Offence (2011), placing pejoratives on the list of "impoliteness formulae", conventionally associated with offense. He talks about impoliteness strategies and connects them with insults (which he sees as "producing or perceiving a display of low values for some target" (2011: 56), and then lists some corresponding impoliteness formulae. Here, we shall be dealing with a prominent class of words that are specialized for use in the context of impoliteness-rudeness (but not limited to it), namely pejoratives-slurs.

As Kent Bach has noted at a conference in Dubrovnik, some of them are related to a particular wide genus like ethnicity or race, say Nigger, Kike (or German words like Saujude, Tschusch, Kanake), cunt (Fotze), some to a narrow range (say pig for policeman) and some target more general properties (asshole, Schweinehund).

The paper is structured as follows: In the rest of the present paper pejoratives are connected to the issues of (im-)politeness and rudeness. In section two they and their counterpart, laudatory terms, are placed on the map of generic expressions, as evaluative, positive and negative generic

\footnotetext{
${ }^{1}$ I wish to thank the organizer, Aneta Stojić, and the participants, for discussion and inspiration.

2 For an overview of the field, cf. Derek Bousfield and Miriam Locher (eds.) (2008).

Linguistik online 82, 3/17 - http://dx.doi.org/10.13092/lo.82.3714
}

CC by 3.0 
terms. Then, we discuss their negative generic content and argue that the content is semantic, even truth-functional. This creates problems with potentially empty reference, to which a principled solution is proposed: the negative hybrid social kind terms hypothesis.

Considerations of rudeness, from the field of socio-pragmatics, suggest at least the following constraints on the content of pejoratives. The relatively neutral ones are first, successful referring, actual hitting of specific target, second, characterizing the target in a recognizable way (Blacks for Nigger, Middle-Easterners for Kanake). Then on the rude, non-neutral side they need offensive ascriptions of properties (primitive, lazy, dangerous), and also suggestions attacking good self-image of the target, his or her "positive face", to use the term from (im-)politeness research. Finally, one could be attacking both "positive" and "negative" face, the lack of constraint from others.

Before proceeding to the task, let us add a requirement on the successful theory of pejoratives. Pejoratives are in their use symmetrical to laudatives: the former negative, the later positive. Consider the word like Aryan (Arier) as used by a racist. It suggests that the target is positive for belonging to a certain race, so it is ideal for "face lifting", the opposite of face attacking. It also suggests (positive) ways of treating the target. In Croatian, we have an analogous word for a good, patriotic Croatian, Hrvatina. English is less rich with such ethnic laudatives; a relatively archaic candidate is Yankee Doodle or just Yankee for a patriotic American. ${ }^{3}$ The same goes for John Bull for Englishmen. "The common orders of English seem wonderfully captivated with the beau ideal which they have formed of John Bull, and endeavor to act up to the broad caricature that is perpetually before their eyes", wrote Washington Irvin almost a hundred years ago. ${ }^{4}$

Another way to produce a laudative is to use "true" or "real" with a generic: a true American, a real man (cf. the excellent discussion in Leslie Sarah-Jane (2015). So much for generic (ethnic, gender-directed and so on) laudatives. On the specific, we have words like "stud" and "saint", praising the target for having certain traits. The use is completely symmetrical to the use of pejoratives. A theory of pejoratives should be usable to derive, e contrario, an account of laudatives. Theories that do not fulfil this condition of full generality are simply to narrow,

\footnotetext{
${ }^{3}$ Remember the song, Yankee Doodle, and consider the kinds of compliments linked to being a Yankee: "I'm the kid that's all the candy, I'm a Yankee Doodle Dandy, I'm glad I am, ... I long to see the girl I left behind me; That ain't a josh, She's a Yankee, by gosh. Oh, say can you see, Anything about a Yankee that's a phony? My father's father was a Yankee too: That's going some, For the Yankees, by gum. Oh, say can you see Anything about my pedigree that's phony? I'm a Yankee Doodle Dandy, A Yankee Doodle, do or die; A real live nephew of my Uncle Sam, Born on the Fourth of July. I've got a Yankee Doodle sweetheart, She's my Yankee Doodle joy. Yankee Doodle came to London, just to ride the ponies; I am the Yankee Doodle Boy."

${ }^{4}$ Here is he relevant material for Washington Irving's John Bull: "If one of these should be a little uncouth in speech, and apt to utter impertinent truths, he confesses that he is a real John Bull, and always speaks his mind. Unluckily, they sometimes make their boasted Bull-ism an apology for their prejudice or grossness; and this I have especially noticed among those truly homebred and genuine sons of the soil who have never migrated beyond the sound of Bow-bells. If one of these should be a little uncouth in speech, and apt to utter impertinent truths, he confesses that he is a real John Bull, and always speaks his mind. If he now and then flies into an unreasonable burst of passion about trifles, he observes, that John Bull is a choleric old blade, but then his passion is over in a moment, and he bears no malice. If he betrays a coarseness of taste, and an insensibility to foreign refinements, he thanks heaven for his ignorance - he is a plain John Bull, and has no relish for frippery and nicknacks. His very proneness to be gulled by strangers, and to pay extravagantly for absurdities, is excused under the plea of munificence - for John is always more generous than wise. Thus, under the name of John Bull, he will contrive to argue every fault into a merit, and will frankly convict himself of being the honest fellow in existence." (Matthews/Brander (eds.) 1914).
}

ISSN 1615-3014 
and missing the scope of evaluative talk (for specific criticism of the prohibitionist theory due to Anderson and LePore using the requirement of full generality, cf. Miscevic/Perhat 2016: 131-133).

On the perlocutionary side, uses of pejoratives seem to have a canonical range of perlocutionary acts associated with them. Most obviously, they are typically used to offend. More interestingly, there is a possibility to connect the typology of typical illocutionary acts tied to the use of pejoratives with levels of their meaning. Here is a way to connect meaning and use to satisfy the demands from pragmatics of rudeness. We need first, the level of successful referring second, the level of characterizing the target in a neutral recognizable way (Blacks for Nigger, Turks for Kanake). Then on the non-neutral side, we need offensive ascriptions of properties (primitive, lazy, dangerous). Fourthly, on the side of suggestions attacking good self-image of the target, his or her "positive face", we can place suggestions of how to treat the target ( $\mathrm{Ka}$ nakes are to be avoided). Finally, one could attack both "positive" and "negative" face by expressing attitudes of anger, contempt and the like. Take the word Nigger:

\begin{tabular}{|l|l|}
\hline LEVEL OF MEANING & PRAGMATICS-IMPOLITENESS \\
\hline $\begin{array}{l}\text { CAUSAL-HISTORICAL } \\
\text { someone called them thus }\end{array}$ & SUCCESSFULL REFERRING \\
\hline $\begin{array}{l}\text { MINIMAL DESCRIPTIVE } \\
\text { Afro-American or Black }\end{array}$ & PLACING THE TARGET \\
\hline $\begin{array}{l}\text { NEGATIVE DESCRIPTIVE-EVALUATIVE } \\
\text { primitive, lazy }\end{array}$ & OFFENSIVE ASCRIPTIONS \\
\hline $\begin{array}{l}\text { PRESCRIPTIVE } \\
\text { to be avoided, discriminated! }\end{array}$ & ATTACKING POSITIVE FACE \\
\hline $\begin{array}{l}\text { EXPRESSIVE } \\
\text { Yuck! }\end{array}$ & $\begin{array}{l}\text { ATTACKING BOTH POSITIVE AND NEGATIVE } \\
\text { FACE }\end{array}$ \\
\hline
\end{tabular}

Table 1

This is not the only possible way to organize the correspondence between levels of meaning and function in face attack, but is a natural and practical one. Of course, various levels will fit with various types of illocutionary acts. The first two, having to do with references, will fit propositional acts, the third will be at home in illocutionary assertive acts, the fourth with directive ("behabitive", to use Austin's term) acts, and the last with expressive ones.

Laudative should have a similar semantic structure. Think of Aryan as used by racists: 


\begin{tabular}{|l|l|}
\hline LEVEL OF MEANING & PRAGMATICS-ADMIRATION \\
\hline $\begin{array}{l}\text { CAUSAL-HISTORICAL } \\
\text { someone called them thus }\end{array}$ & SUCCESSFULL REFERRING \\
\hline $\begin{array}{l}\text { MINIMAL DESCRIPTIVE } \\
\text { Caucasian }\end{array}$ & PLACING THE TARGET \\
\hline $\begin{array}{l}\text { POSITIVE DESCRIPTIVE-EVALUATIVE } \\
\text { noble, brave etc. }\end{array}$ & LAUDATIVE ASCRIPTIONS \\
\hline $\begin{array}{l}\text { PRESCRIPTIVE } \\
\text { to be helped, supported if needed! }\end{array}$ & EXTOLLING POSITIVE FACE \\
\hline $\begin{array}{l}\text { EXPRESSIVE } \\
\text { Vow! }\end{array}$ & $\begin{array}{l}\text { EXTOLLING BOTH POSITIVE AND NEGATIVE } \\
\text { FACE }\end{array}$ \\
\hline
\end{tabular}

Table 2

The parallel is complete and we might need a unitary account for both.

\section{The negative generic content: semantic or pragmatic?}

Let us therefore place our object of research, pejoratives (together with laudatory expressions) on a map. Little has been said in the literature on this issue; here we shall tentatively connect it to the notion of generics. Generic noun phrases are kind-referring like dogs in Dogs are mammals, a typical generic (or generic sentence). ${ }^{5}$ The typical pejorative sentences, like Niggers are dangerous seem to belong to the same class, and Nigger seems to be a generic noun. All kind of pejorative fit into the picture, not only the ones called "generic" by K. Bach, but also the subgeneric and specific. Is there a systematic story to be told from generics research? Here is a possibility: pejoratives are generic nouns that contain evaluative component, indeed a negative one. Laudatory expression contains a positive one.

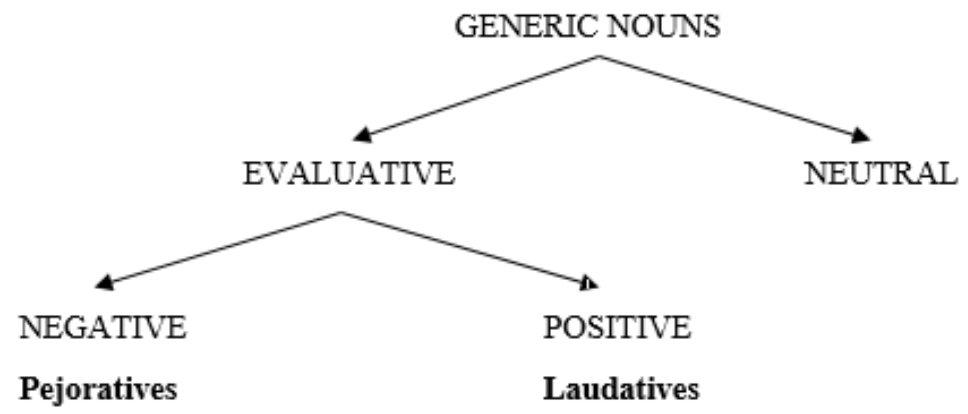

Figure 1

How should we understand pejorative generics? Let us follow a general perspective from generics research. One line is particularly well suited for pejoratives, namely that generic sentences are evaluated for their truth value with respect to rules and regulations. We propose we understand rules to encompass natural and social-science laws and quasi-laws. Aron Cohen illustrates it with a simple example: /A/ raven is black is true not because of the properties of individual ravens, but because there is a (biological) rule stating that ravens are black (Cohen

${ }^{5}$ Cf. Carlson/Pelletier (1995: 2). 
2005: 377). Applied to pejorative sentences this will suggest an expression of presumed stereotypical rules as the main kind of pejorative generics.

Let us focus upon our relevant sub-kind of generic expressions, pejoratives. We shall briefly treat two main questions concerning their semantics. How do they manage to refer? And how should we treat their negative content? Let us start with the second question. Prima facie, the bad assumptions are part of the meaning (in a wide sense of the term) of the pejorative. Are there obstacles to identifying the core bad assumptions about the targets of a given use of a pejorative $\mathrm{P}$ with the meaning of $\mathrm{P}$ ? A popular but not super reliable test is the following question: suppose a person, A, does not know about these assumptions. Does she know what "P" means? Does a visitor who knows that nigger refers to Afro-Americans, but has no idea about the stereotype of Afro-Americans associated with nigger know the meaning of the term? Is it appropriate to tell her that you will teach her the shocking meaning of the term? Our hunch is that it is. The same for other pejoratives. Here is the entry for bitch in John Ayto: The Oxford Dictionary of Slang. It begins by listing the most general meaning, common to several bad words: "An unpleasant or despicable female person". And goes on to note: "The majority of opprobrious epithets applied to women contain, or can contain, some suggestion of immorality, particularly sexual promiscuity [...] (1400). ${ }^{6}$ In early use often applied specifically to a prostitute, and latterly often applied specifically to a malicious or spiteful woman; from earlier sense, female dog [...]"' (2000: 228)

Similarly, Random House Dictionary (1994) specifies the meaning of cunt when applied to a male: "a despicable, contemptible or foolish man". None of the example in itself clinches the point, but taken together they re-enforce the prima facie plausible assumption that claims about "uncivilized manners", "slave-like status or behavior", and the like just enter the meaning of the slurs in question. In other words, if stereotypes associated with pejoratives are listed as their meanings, and the ascription of properties etc. indicates that they belong to the meaning of the slur, then pejoratives are not purely performative and expressive, but semantic. ${ }^{7}$

The same goes for correspondences between languages. The Collins English-German Dictionary entry for bitch: (= woman, as they put it), offers two direct equivalents, "Miststück" and "Hexe", noting that they are "spiteful". The expression don't be a bitch is rendered as sei nicht so gemein or gehässig, and she's a mean bitch as sie ist ein gemeines Stück.

This brings us to a general statement about lexical-semantic meaning. Consider five criteria, compiled from literature and listed by Zoltan Gendler Szabo in his introduction to Semantics vs. Pragmatics (2005: 6):

\footnotetext{
6 The year 1400 refers to the first appearance of the term.

${ }^{7}$ Standard dictionaries indeed talk about senses of slurs, exactly in terms of stereotypes and figurative origins that we sketched. Geoffrey Hughes notes for instance the following: In his Classical Dictionary of the Vulgar Tongue (1785), Francis Grose noted that the basic term negro carried the sense of "slave" in uses like "I'm no man's Negro" (2006: 327). And he comments: The history of the term in the southern United States is obviously colored by the slave relationship. Similarly, with the South African equivalent, the term "kaffir" for black people: From the earliest accounts, the stereotype of the savage predominated, especially in the categorization of the "red" or "raw" kaffir, so called because of the red ochre that they smeared on their bodies. In their Zulu Dictionary (1948), C. M. Doke and B. W. Vilikazi included the following usage note: "Term of contempt for a person (black or white) of uncivilized manners (a swearword if used direct to a person)." (2006: 281).
} 
a. Competence: Typically, some but not all of what the speaker conveys could be grasped by any competent speaker without special knowledge. Seems that if holds for our pejoratives, say bitch and nigger: any competent English speaker can grasp the negative material the speaker conveys. The same for laudatives.

b. Encoding: This is just the presence in the dictionaries we started with.

c. Compositionality: Typically, some but not all of what the speaker conveys is compositionally determined (by the syntax and the lexicon).

d. Rules: Typically, some but not all of what the speaker conveys can be ascertained by following rules, as opposed to elaborate cognitive strategies. What elaborate cognitive strategy do you need to understand what the speaker conveyed by calling his female boss a bitch? None.

e. Truth-conditionality: "Typically, some but not all of what the speaker conveys is truthconditionally relevant." This is of course, debatable, and denied by relevance theoreticians, but we shall argue for truth conditionality of negative content briefly later.

f. Intention-independence: "Typically, some but not all of what the speaker conveys is independent of the speaker's specific intentions to talk about this or that."

Holds indeed! Most theoreticians agree that the derogatory content of pejoratives is independent from speaker's intentions. So nearly all criteria offered classify pejoratives in the same way; this strengthens the case for semantic nature of the bad content (and, analogously, for good content of laudatives). Let us mention a problem for the alternative view, that proposes austere semantics for pejoratives, claiming that a word like Kanake just means Turk, Boche means German and the rest is a matter of pragmatics (as relevance theory and minimalism do). It is a problem concerning hearer's motivation to search for further content: $\mathrm{S}$ and $\mathrm{H}$ are discussing Lessing's nationality. S says Lessing is a Boche. Its semantic (truth-conditional content) is Lessing is German. This is true. So, $\mathrm{H}$ is getting a true sentence which sounds like a complete piece of information given the topic. Why would she then go on and ask for additional implied meanings? Or, if you want a relevance version: what $\mathrm{S}$ said is clearly relevant for the discussion, even maximally relevant. So, why search further? It is very different from metaphor: James is a Laocoon, and his three colleagues are the snakes. Clearly false, crying out for further probing.

\section{The issue of reference: the negative hybrid social kind terms hypothesis}

Here is our proposal, developed from a hint of Michael Devitt some years ago, and compatible with various causal or causal-descriptive theories in the field. ${ }^{8}$ Pejoratives are negative (derogatory) social kind terms, with hybrid nature. Their referential apparatus involves casual history of naming plus descriptive-evaluative senses. The later have a neutral part (given by a neutral description (German, Croat, female, gay), and the bad part (primitive, hateful, stupid etc.), plus more, some prescriptive and some expressive material. A part of descriptive sense, the one that goes with neutral description is itself neutral, and could (co-)ground reference, the other part is

\footnotetext{
${ }^{8}$ For instance, Recanati's view of mental files (2012); let me thank my student Mirela Fuš for pointing to parallels with Recanati.
} 
negative and is most often filled with false stereotypes. So, ours is a social kind term hypothesis: ethnic, gender and similar pejoratives are generic terms that stand for presumed (and often real) social kinds to which they ascribe all sorts of negative properties. Since it combines causal account with the descriptive approach, it would be a hybrid theory, all in all a hybrid social kind theory. We shall leave the causal part aside here, and concentrate upon the descriptive (and evaluative) components.

Consider now the accounts of kind terms offered by causal reference theorists, primarily Devitt, but also Recanati. Talking about artifactual terms, like pencil, Devitt, (in Devitt/Sterelny 1999) notes three components that determine the reference: first, the original naming, second, the transmission of the term up to the present use, and third the description, appealing to the intended use and to the fact that the object has a graphite at its center. He calls the resulting theory the "hybrid theory of reference". Here are the first steps: The descriptive-causal theory of reference fixing for basic "artifactual" terms is analogous to that for natural kind terms. The descriptive element is taken over from the description theory. It is the description of physical characteristics (graphite for pencil, back for chair). The causal element arises from grounding in samples. Whereas on the description theory, the reference-determining function is fixed by an associated description of the function, on the descriptive-causal theory it is fixed by the objects in the sample used to ground the term. The term refers to any object (with the physical characteristics) that has the same function as the objects in the sample (1999: 98).

He also notices the problem of "cases where religious or social beliefs mystify the function of certain artefacts" (1999: 99). We shall look at a possible parallel with our cases. Let us now extend the proposal - hybrid theory of reference - to social kinds. Teacher is a social kind term: presumably grounded in some ancient act of naming and in the chain of transmission of name extending up to the present use (or, in internalist mode, in the assumptions about such an act of naming and about transition). However, it also has a descriptive meaning: people who regularly (and perhaps as a matter of profession) teach somebody. The two could have come in conflict, but didn't. (Imagine that in the original teacher's group there was a person who in fact didn't teach; or several persons, and so on.) So, teacher has both causal and descriptive aspect.

Focus now on cases where religious or social beliefs mystify the characteristics of typical and definitory activities of certain social groups. Consider the generic term medicine man. A relevant original group has been thus designated by original speakers (leaving the issue of translation aside). They were performing activities called by them and their audience "casting spells" and were assumed to have magic powers. The last assumption is, we submit, false. The "casting spells" characterization is ambiguous: first, it can mean pronouncing words and performing gestures that actually do produce results in a super-natural way, second, pronouncing words and performing gestures that are believed to produce the results in such a way by the relevant group of people, including the "medicine men" themselves. Consider now the sentence, concerning three official "medicine men" of a given tribe, $\mathrm{O}, \mathrm{Lo}$ and Bo: $O$, Lo and Bo are medicine men. Is it true or false? Well, what about magic powers? Presumably, O, Lo and Bo do not have magic powers; so it is literally false since they lack magic power. But, in the mouth of an anthropologist the sentence probably expresses the proposition that the three men do perform the required activities and are taken to have magic powers. This second proposition is true. Similarly, with astrological generic terms like "Scorpio". The meaning of the term involves the date 
of birth, and assumption about character traits (dangerous, intelligent etc.). So, Nenad is a Scorpio is true of the author of the paper, born on Nov. 1., but the author doubts that he has the requisite 'Scorpio' traits, and even if he has them, he is sure that this is not the case in virtue of him being born at the right interval.

The double determination of reference places pejoratives in a much wider group of problematic social and psychological kind terms, that encompasses terms that are value-neutral, not expressive, let alone offensive, as pejoratives are, but that exhibit the same correct/incorrect duality. In our examples of medicine man and Scorpio the superstitious component exhibits similar behavior that the derogatory component exhibits in the case of pejoratives. The parallel between Boche and medicine man/Scorpio is clear. Boche would fail to refer, in virtue of its derogatory content alone, like medicine man, strictly taken in its superficial meaning, would. But the causal and minimal descriptive part do secure the reference, and we, hearers, reconstruct the reference to Germans, from the minimal neutral descriptive part, the way we do with other sentences involving dubious kind terms. So, to return to the Lessing example, Lessing was a Boche involves something like: $L$. was a German, then $L$ belonged to the nation consisting of people, known as Germans, who are cruel because members of this nation or, shorter: L. was cruel because German. We agree that there is no nation the members of which are cruel just in virtue of belonging to it, so for the reference, in specific contexts, we focus on the true and decent proposition. L. was a German. Consider now Lessing was an Aquarius. Well, Lessing was born at the right time of the year to be an Aquarius; but we don't think his character traits come from this fact.

So, let us now restate the main point of this proposal: pejoratives, say "N", are negative (derogatory) generic social kind terms, with hybrid nature. Their reference is partly determined by causal chain: the target group or social kind $\mathrm{K}$ has been called by somebody " $\mathrm{N}$ ", the name has been transmitted to the present users, and it refers to $\mathrm{K}$ and its members. Take faggot; assume that the speaker has had a direct or indirect epistemic contact with homosexuals (indirect meaning that he knows someone who knows some homosexuals, and has got the term from them). This secures causal-epistemic connection. The rest is descriptive-evaluative. So, we have a neutral part, i. e. the neutral dimension (given by a causal chain, and, in our characterization, by a neutral description (gay, Afro-American, Croat, female), joined to the bad part, i. e. the negative descriptive-evaluative dimension (primitive, hateful, stupid etc.) plus more: certainly the expression of negative emotion, hatred, contempt and the like, and probably some prescriptive suggestion about how to treat the target and her kind. A symmetric proposal for laudatory expression would replace the negative evaluative a content with a positive one, and negative prescription with a positive one. Let us call the proposal for pejoratives the negative hybrid social kind terms hypothesis (NHSKT hypothesis); the equivalent for laudatory expressions would be the positive hybrid social kind terms hypothesis.

Before concluding, here is one more problem: what if social kinds are very much unlike the natural ones, so they cannot be referred to by causal contact, epistemic familiarity and the like? ${ }^{9}$ Answer: if this is the case, the reference is determined in a purely descriptive way: Serbs, Germans, Afro-Americans, women, gays. But then, what does the derogatory material (descriptiveevaluative) do? Why is it part of the sense? Well, with thick concepts things sometimes stand

\footnotetext{
${ }^{9}$ Cf. Fuš (2016).
} 
this way: when strong sexual desire is (re-)conceptualized as "lust", the referents are cases of strong sexual desire. We could apply the same idea here; but in order to do this properly, the parallel with thick concepts would have to be worked out. Let us leave it at this for the occasion.

We can now address the value-laden content postulated by the NHSKT theory, according to which pejoratives are negative hybrid social kind terms, and treat it as a dimension of their meaning. The dimension orders bad properties ("vices") ascribed to the members of the target group (often with insinuation that they have these properties in virtue of their belonging to the group). We shall assume that the properties are usually taken from the relevant stereotype. Here are our two examples:

\begin{tabular}{|l|l|l|}
\hline Example & Boche & curr \\
\hline Minimal descriptive & German & dog \\
\hline Negative descriptive-evaluative & cruel and dangerous because German & dangerous, of low origin etc. \\
\hline
\end{tabular}

Table 3

As mentioned, we take the second row to exemplify a dimension of meaning of pejoratives, i. e. the negative descriptive-evaluative one. We assume gradation in badness since some pejoratives are more devaluing than others, for example in English: the negative value implied by minx is not so dramatic as the one belonging to whore (Hughes 2006: 163). We can have a plurality of closely related dimensions, say typical negative properties plus their degree of badness.

This is the place to address the theories that take the opposite view, and place the negative evaluative content outside semantics, and into pragmatics. The proponent of such a view might seek a useful analogy with recent theories of thick concepts. The original story of thick concepts, as told by B. Williams (1985), was that they carry the moral-evaluative attitude on their sleeves, plus that the attitude is fixed within a very narrow range: courage is admirable, period. Change the attitude, and the concept is gone.

An old favorite is the concept lewd, introduced into philosophical discussion many years ago by Gibbard (1992). We suppose lewd covers descriptive features that have to do with overt sexual display and mockery of normal proprieties, and the negative evaluative features or at least a negative reaction of the speaker. To illustrate, the person who criticizes, say, Lady Gaga's performance for being lewd means that it was overtly sexy. If the evaluated it positively he could have described it as "hot" (a positive thick term). However, he clearly evaluates the performance negatively; he doesn't say hot, but lewd. And he expects his audience to agree. Now, Pekka Väyrynen has recently (2013) proposed a pragmatic view of such concepts: the semantics of the word would cover just the descriptive "at issue" content, whereas the evaluations ("T-evaluations" as they are called) are part of pragmatics. So, on this pragmatic view "global T-evaluations are implications of T utterances which are normally "not at issue" in their literal uses in normal contexts, and which arise conversationally" (2013: 127). 
- T-users (for the most part) accept the relevant T-evaluations.

- The relevant T-utterances (for the most part) accurately reflect T-users' acceptance of those evaluations.

- $\quad$ Both of these facts are common knowledge. (2013:134)

The evaluative use exhibits Parochiality: The application of a thick term or concept tends to derive its point or interest from the term's or concept's relation to the evaluative perspective reflected in its application (2013: 128).

Here is the rationale: "I have been suggesting that the Pragmatic View can exploit Parochiality to explain how T-evaluations could be part of the default interpretation of literal T-utterances in normal contexts..." (ibid.).

One could simply extend the proposal from adjectives to nouns, and claim that pejorative contents exhibit the same structure: like in thick concepts, the negative content is purely pragmatic.

However, the proposal does not seem to work, and here is - briefly - why. Suppose we accept Parochiality: the application of a pejorative term or concept, say Boche, tends to derive its point or interest from the term's or concept's relation to the evaluative perspective reflected in its application. This covers the evaluative-prescriptive component of content, and come close to covering its expressive component. But does this force us to accept Pragmatic View and claim that T-evaluations are implications of T-utterances which are normally "not at issue" in their literal uses in normal contexts, and which arise conversationally?

Let us use "P" for pejorative; so P-sentence will be one containing pejoratives, and so on. It is true that general conversational norms regarding informativeness, efficiency and so on might be used to explain why, given these assumptions, people can reasonably infer from a P-utterance that the speaker accepts the relevant P-evaluations unless something in the particular context suggests otherwise. But, thick pragmatic relies on mutual acceptance. "If one point of mutually accepted P-evaluations is to regulate the attitudes of P-users, this is further support for interpreting P-utterances as conveying P-evaluations. This kind of a regulative role would give conversations among P-users about whether something falls under $\mathrm{P}$ an evaluative point and explain why P-objectors would typically have little at stake in such discussions." (2013: 128)

The $2^{\text {nd }}$ person use of pejoratives to derogate and offend is, at least prima facie, quite different. No mutual acceptance is presupposed, on the contrary. It is more like the very meaning of the word carries the relevant levels of evaluation and prescription, no matter whether the interlocutors agree, or violently disagree, about the qualities of Germans, Blacks or homosexuals.

Note that the model of thick concepts might be inappropriate because of the difference of use. We are not advocating the pragmatic view on thick concepts, in fact, we are quite against it. But even if the view were adequate for thick concepts, here is an interesting difference. If a lewd-user uses the term to condemn an overt display of sexuality, her primary context of use will be the one of agreement on attitude. One can criticize such displays in the $3^{\text {rd }}$ person, to a like-minded audience. But also, it makes little sense to chastise a behavior to a person who is lewd-objector as being lewd. Typically, one chastises the person hoping that she shares the attitude toward such displays, not expecting that she finds the term itself deeply problematic. If the latter, the chastising is doomed to failure, and the utterance becomes pointless. 
On the other hand, a homophobe addressing someone as You faggot, does not expect agreement. The whole point of the utterance is to use a word with a content that a gay person rejects, to remind the person of the whole range of negative evaluations and prescriptions (plus attitudes) it carries with it. For this, conventional meaning is way more appropriate, than the expectation of pragmatic agreement. Homophobes are not that stupid.

So much for the pragmatic alternative. Let us return to our proposal. Hybrid terms in general can carry false components in their senses: one can refer to sofa even if one has false beliefs about it, as Devitt has noted (1999: 98). There is a lot of social kind terms associated with partly false concepts, and this does not prevent the terms for referring. The same can happen with natural kind terms: for example, at the beginning of the study of electrons, they were defined in a manner involving false hypotheses, e. g. that they are the smallest particles out of which all matter is made. What won was the causal connection, linking the use of the term with the phenomena observed in primitive cathode ray tubes. ${ }^{10}$ Notice an interesting division of social kind terms. The ones like teacher, Croat, women are referentially relatively unproblematic (even if there is an element of "social construction" in the constitution of their referential domains). But what about medicine man, theta-rayshealer, or close psychological kind: Scorpio, Libra? They seem referentially problematic in the way reminiscent of our present problems with pejoratives. We have mentioned medicine man above. Now, this extremely general phenomenon, not limited to evaluative components, offers a fine solution to the trouble with the reference of pejoratives. They refer thanks to their first dimension, the neutral one (involving probably neutral descriptive plus causal elements). This kind of determination of reference, where sense contains false elements, both predicts the extant trouble with the truth-status, and offers the means to solving it.

Of course, the presence of both causal-historical and descriptive components brings problems in its wake. ${ }^{11}$ One is the diversity of meanings various people associate with a given pejorative (the problem of unwanted ambiguity or idiolect). As Michael Glanzberg and David Braun were noting in our discussion, not everybody has the same stereotype, there are non-standard stereotypes and one can refer to the right target in spite of one's ignorance of stereotype. I can ask Is a German a Boche? in a more reasonable matter than if I asked Is a German a German? noted Braun. And, I can still pose the question, thought I don't know the answer, he added. Answer: All this is valid for other concepts as well. We can diverge from our co-speakers in having eccentric views on some item, or just being shamefully ignorant, and still refer. We hope a minimal common denominator can be found.

The other is the issue of principled criterion: which components are really parts of meaning, and which are not? We have to leave it for another occasion.

Instead, let us mention a wider problem that can be solved by using the hybrid social kind theory. Suppose, as it is reasonable to do, that the descriptive-evaluative component contains a lot of material that is in fact false about the targets: the use of Boche, and even more Hun

\footnotetext{
${ }^{10}$ I owe this information to Robert Nola and his talk at Dubrovnik IUC conference on Philosophy of science, in April 2014 entitled "Realism, Reference, Ramsification and Causal Descriptivism: the case of the electron as an illustration".

11 Thanks go to Michael Devitt for pressing me on this topic.
} 
suggests that the target is cruel-because-German. So, what about generics, and other sentences, formed with the help of pejoratives? In front of a block in a town in Germany Hans says: $\mathrm{Ka}$ nakes live here. He means Turks, with all the bad qualities the term Kanake ascribes to them. ${ }^{12}$ Is his sentence true? In a way yes, if Turks really live on the block. Emphatically no, if the sentence ascribes to them all the relevant negative properties.

To use Tim Williamson's example Lessing was a Boche expresses at least two propositions: first, L. was a German. the true and decent one, and then L. was cruel because German. the false (and indecent) one. But if nobody is cruel just because German (or dangerous because gay etc.) then Bochel Hun (and faggott) do not refer. Some authors, like Christopher Hom $(2008,2010)$, are ready to swallow this counterintuitive consequence. But the price seems too high to pay: saying that pejorative sentences are true makes us, theoreticians, agree with what they claim, which we do not want to.

An elegant middle way is to claim that the sentence expresses a plurality of propositions. Depending on context, the neutral one comes to the fore, and is evaluated as true. Or, the negative one claims hearer's attention. And this one is false. ${ }^{13}$

The phenomenon of plurality has been noted for the whole range of generics. Bernhard Nickel (2016: 62) illustrates it with a completely neutral sentence about bears. Consider the examples in (8):

(8) a. Bears walk on four legs.

b. (In the circus for our entertainment,) bears ride unicycles.

c. (In the circus, bears don't like riding in trucks. Instead,) bears ride on trains.

And he comments:

In different contexts, each of (8a)-(8c) might express a truth. The easiest is (8a), but as continuations of the parenthetical texts in (8b) and (8c), the latter express truths, as well. The reason these possibilities exist is that different respects of normality are relevant for the interpretation of the generics in their respective contexts (ibid.).

Nickel's diagnosis is very general (2016: 62): Because generics are context-dependent - because a single generic can express different propositions in different contexts - we can no longer simply describe propositions by mentioning a generic. There is no such thing, for example, as the proposition that bears ride unicycles. There are several propositions that the sentence bears ride unicycles could be used to express and which it is depends on the context, specifically on what respects of normality are relevant. Strictly speaking, we now need to indicate the context with respect to which a generic is to be interpreted. However, in many cases, the context is obvious, and we'll continue to describe generic propositions as we have so far.

Of course, this is not the end of the story. Many authors, for instance M. Richard, point out that the use of pejoratives often involves a prescriptive suggestion: the target is to be despised (Richard 2008: 15), others would add avoided, or discriminated against, because she exemplifies the

\footnotetext{
${ }^{12}$ Compare Richard (2008:7) and Miščević/Perhat (2016, section A, 1).

${ }^{13}$ I thus accept the idea of the plurality of propositions expressed by sentence figuring a pejorative, proposed by Potts $(2005,2006)$ and Bach (web), who claim that a typical pejorative sentences expresses a plurality of propositions. In contrast to Potts, I will not assume that they are organized by relations of conventional implicature.
} 
properties from the negative descriptive content. Fags will burn in Hell is a well-known variant of such prescriptivism, directed to the future and eternal suffering of gays. The legal debate about hate speech "instigating to cause physical harm" (cf. e. g. Cohen-Almagor 2001), is an important ongoing dialogue testifying to the relevance and importance to this prescriptive dimension. On the other hand, it is hard to pin down any exact type of prescription (involving either obligation - one should despise Xs, or permission - it is socially and morally allowed to do such-and-such to Xs) that would be non-problematically attached to any particular pejorative. So, allow us some optimism in the matter, and let us tentatively point to two possible connected dimensions of the prescriptive meaning (in the wide sense). The first is more clearly semantic, and it concerns the gravity of suggested actions and in general treatments of X; along this dimension we would have ordered (partially or completely) suggested treatments: e. g. it is morally permissible to deride Xs, it is obligatory to deride Xs, (that would fit, say, a mild pejorative), then it is morally permissible systematically to avoid Xs, and then obligatory to do so (this would fit a moderately nasty pejorative), all the way to it is morally permissible to kill Xs. The second dimension might have to do with the subjective strength with which the prescription is made; this one might be more pragmatic and situation-dependent. We will leave matters at this, but the interested reader might wish to consult Saunders (2011) and Perhat's (2012) discussion of Saunders for further material.

This ends the strictly semantic part. We can now briefly mention the emotional-expressive content and the corresponding dimension (or a small bundle of dimensions). Using a pejorative, the speaker expresses his own negative emotional attitude to the target. Let us say a few words about this content. An elegant way to represent it is to take it as placing the target to a point in the emotional space of the speaker (often with the hope that the hearer shares the same space). Think of the space as of a representation of emotional qualities, from positive, through neutral to negative; the target of pejorative will be on the negative side. Stefano Predelli is suggesting something like this in his (2010). The main emotional-expressive dimension goes on the negative side, the one that is relevant to our topic, from mild dislike (Lime) through intermediate stages of contempt and hate (Boche), all the way to intense hatred (Hun). A more careful analysis would at least distinguish dimensions of dislike-to-hate, of anger and of contempt, so that our emotional-expressive dimension would end up as a resultant, a vector sum, if you want, of at least these three. So, let us switch the example to the particularly offensive one, and summarize the levels of content:

\begin{tabular}{|c|c|}
\hline IN SUMMARY: & PEJORATIVES \\
\hline EXAMPLE & Nigger \\
\hline MINIMAL DESCRIPTIVE & Afro-American \\
\hline NEGATIVE DESCRIPTIVE-EVALUATIVE & primitive, lazy, dangerous \\
\hline PRESCRIPTIVE & to be avoided, discriminated! \\
\hline EXPRESSIVE & yuck! (and more) \\
\hline
\end{tabular}

Table 4 
The causal-historical and negative descriptive evaluative dimensions (or layers) of meaning are semantic and that the expressive meaning might be more related to the actual speech act, although its potential is coded in the negative descriptive level. Of course, one would welcome a formal-semantic treatment of the expressive dimension (perhaps along the lines of Kaplan (ms.) and Predelli 2010), but the treatment would not have to make it literally part of the semantics in the strict and traditional sense.

\section{Conclusion}

Integrating diverse areas of research on offense "light and winged words" can hurt and offend, Plato noted in his "Laws" (717). Optimistically, he suggested that Nemesis, "messenger of Justice" keeps watch over them. We are reasons to be less optimistic: hate speech and linguistic violence are scattered all over Facebook and similar media.

Here, we have discussed a class of words specialized for verbal rudeness and offence, namely pejoratives, placing them firmly within the context of the pragmatics of rudeness. We have noted their symmetric counterpart, laudatory expressions. We have placed both on the map of generics (as two kinds of evaluative generic nouns, positive and negative) and proposed a brief but potentially unitary account that can be easily extended from the former to the later. The account for both classes is strongly semanticist, and here we concentrated on pejoratives.

Typically, pejoratives manage to refer to their target, and typically, they carry with themselves meanings that falsely ascribe negative properties to the target. How is the combination possible? The mechanism of reference is causal-historical: Kanake predominantly refers to Middle-eastern ethnic groups because they have been so called in the past, and the reference was transmitted to our times. The mechanism of ascription is descriptive. The coexistence of two mechanisms is limited to pejoratives, not ad hoc; it can be encountered in other names for kinds, artificial, social and the like. We dubbed the proposed account "the negative hybrid social kind terms hypothesis".

The levels of meaning of pejoratives thus encompass the neutral-descriptive one, the negative evaluative one and the prescriptive one, all on the semantic side. The expressive dimension is also present, but here it is left open if it is part of narrow semantic meaning. Now, if a lot of semantic material in a pejorative is false, doesn't this make all pejorative generics empty? No, because a pejorative generic sentence normally expresses a plurality of propositions (as other generics presumably do). Some of them are neutral and true, some negative evaluative and false.

The plurality of levels nicely fit the role of pejoratives in rude communication and verbal violence. The neutral level identifies the target others perform the "face attack". This offers a possibility to integrate the insights from three areas of research: generics, semantics of pejoratives (and of laudatory expressions) and the (im-)politeness theory from social pragmatics (the legal discussion of fighting words might join in). We hope that the first step has been done here.

\section{References}

Carlson, Gregory/Pelletier, Francis J. (1995): The Generic Book. Chicago: University of Chicago Press. 
Cohen-Almagor, Raphael (2001): Speech, Media and Ethics. The Limits of Free Expression. London: Palgrave.

Cohen, Ariel (2005): “Genericity”. In: Strazny, Philipp (ed.): Encyclopedia of linguistics. New York, Taylor \& Francis Books Inc.: 376-377.

Culpeper, Jonathan (2008): "Reflections on impoliteness, relational work and power". In: Locher Miriam A./Bousfield Derek (eds.): Impoliteness in Language. Berlin, Mouton de Gruyter: $17-44$.

Culpeper, Jonathan (2011): Impoliteness: Using Language to Cause Offence. Cambridge: Cambridge University Press.

Devitt, Michael/Sterelny, Kim (1999): Language and Reality-An Introduction to the Philosophy of Language. Massachusets: MIT Press.

Fuš, Mirela (2016): "Pejoratives as Social-kind Terms". In: Miščević, Nenad/Perhat, Julija (eds.): A word which bears a sword, inquiries into pejoratives. Zagreb: Kruzak.

Gendler Szabo Zoltan (ed.) (2005): Semantics vs. Pragmatics. Oxford: Clarendon Press.

Gibbard, Allan (1992): Wise Choices, Apt Feelings, A Theory of Normative Judgment. Cambridge/Massachusetts: Harvard University Press.

Hom, Christopher., (2008): "The Semantics of Racial Epithets". Journal of Philosophy 105/8: 416-440.

Hom, Christopher, (2010): "Pejoratives". Philosophy compass 5/2: 164-185.

Hughes, George (2006): An encyclopedia of swearing: the social history of oaths, profanity, foul language, and ethnic slurs in the English-speaking world. Armonk: M. E. Sharpe.

Kaplan David (ms.): The Meaning of Ouch and Oops. http://eecoppock.info/PragmaticsSoSe2012/kaplan.pdf [10.02.2017].

Miščević, Nenad/Perhat, Julija (2016): A word which bears a sword, inquiries into pejoratives. Zagreb: Kruzak.

Leslie, Sarah-Jane (2015): “'Hillary Clinton is the only man in the Obama administration': Dual Character Concepts, Generics, and Gender.“ Analytic Philosophy 56/2: 111-141.

Leslie, Sarah-Jane (ms.): “'Real Men': Polysemy or Implicature?”. To be published in Analytic Philosophy. https://www.princeton.edu/ sjleslie/Real\%20Men\%20Polysemy\%20or\%20 Implicature\%20final.pdf [10.02.2017].

Locher, Miriam A./Bousfield, Derek (eds.) (2008): Impoliteness in Language: Studies on Its Interplay with Power in Theory and Practice. Berlin: de Gruyter.

Nickel, Bernhard (2016): Between Logic and the World, An Integrated Theory of Generics. Oxford: Oxford University Press.

Perhat, Julija (2012): "Review of Saunders (2011)." Croatian Journal of Philosophy 12/34: 111-116.

Predelli, Stefano (2010): "From the Expressive to the Derogatory: On the Semantic Role for Non-Truth-Conditional Meaning." In: Sawyer, Sarah (ed.): New Waves in Philosophy of Language. London, Macmillan: 164-185.

Recanati, Francois (2012): Mental Files. Oxford: Oxford University Press.

Richard, Mark (2008): When Truth Gives Out. Oxford: Oxford University Press.

Saunders, Kevin (2011): Degradation: What the History of Obscenity Tells Us about Hate Speech. New York: New York University Press.

Väyrynen, Pekka (2013): The Lewd, the Rude and the Nasty: A Study of Thick Concepts in Ethics. Oxford: Oxford University Press. 
Williams, Bernard (1985): Ethics and the limits of philosophy. Cambridge/Massachusetts: Harvard University Press. 